www.pjicm.com

https://doi.org/10.54112/pjicm.v2021i1.9

Pak. J. Inten. Care Med., volume 2021: 9

MEDEYE

Original Research Article

\title{
BENEFICIAL EFFECTS OF TREATMENT WITH TOCILIZUMAB IN MODERATE TO CRITICALLY ILL COVID-19 PATIENTS
}

\author{
RANA MA ${ }^{1}$, HASHMI MS ${ }^{2}$, PERVAIZ R ${ }^{3}$, QAYYUM A ${ }^{4}$, SAIF MMU ${ }^{5}$, MUNIR MF ${ }^{5}$, HAFEEZ MM ${ }^{6}$ \\ 1. Head Department of Critical Care, Division of Medicine, Bahria International Hospital, Lahore, Pakistan \\ 2. Consultant Physician, Department of Critical Care, Division of Medicine, Bahria International Hospital, \\ Lahore, Pakistan \\ 3. Senior Registrar, Department of Critical Care, Division of Medicine, Bahria International Hospital, Lahore, \\ Pakistan \\ 4. Head Department of Nephrology, Division of Medicine, Bahria International Hospital, Lahore, Pakistan \\ 5. Department of Critical Care Nursing, Division of Medicine, Bahria International Hospital, Lahore, Pakistan \\ 6. Department of Research \& Development, Expert Doctor PVT, LTD, Lahore, Pakistan \\ *Correspondence: Email: mansoorhafeez140@gmail.com
}

\section{KEYWORDS \\ SARS-CoV-2,}

COVID-19,

Inflammatory markers,

PF ratio,

TOCILIZUMAB

Received $17^{\text {th }}$ June 2021;

Revised $23^{\text {th }}$ November 2021;

Online $19^{\text {th }}$ December 2021

\begin{abstract}
Introduction: COVID-19 virus initiates an inflammatory response in the body involving many cytokines. Interluukin-6 (IL-6) is one of them, elevated levels of which found to be directly related to morbidity and mortality of infected patients. The aim of the current study was to evaluate the clinical benefits of Tocilizumab, a monoclonal antibody against interleukin-6 receptor, as a therapeutic agent for the treatment of Coronavirus disease 2019. Methods: The current retrospective study was conducted at Bahria Town International hospital from rom May 1st to 5th July 2020. Total of one twenty $(n=120)$ moderate to severely ill patients (94 males and 26 females), infected with SARS-CoV-2 virus, were included to assess the effect of TOCILIZUMAB in improvement of $P F$ ratio and other biochemical variables of prognostic importance, including CRP, serum ferritin levels, D-dimers and LDH. These parameters were compared before and after the ten days of treatment with tocilizumab. Demographic, laboratory and clinical finding were recorded for the feather analyses. Statistical analysis was performed by using software SPSS version 21.0. The Wilcoxon signed-rank test used to compare parameters whenever appropriate. A P-value of less than .05 was considered statistically significant. Results: The results of our study showed statistically significant improvement in PF ratio and decrease in CRP levels. Other parameters such as D-Dimer, Serum ferritin levels and LDH showed no change before and after treatment with tocilizumab. Conclusion: In summary, TOCILIZUMAB improved the PF and CRP ratio in COVID-19 patients, but other markers did not improve in response to TOCILIZUMAB in critically ill COVID-19 patients.
\end{abstract}

hypoxia, acute respiratory distress syndrome, and multi organ failure. Such patients may require admission to an intensive care unit (ICU) for critical support and mechanical ventilation (Ali et al., 2020; Huang et al., 2020).

Patients with severe COVID-19 quickly progressed to acute respiratory failure, pulmonary edema and acute respiratory distress syndrome (ARDS) (Xu et al., 2020). ARDS is the leading cause of mortality in COVID-19 patients (Huang et al., 2020; Mady et al., 2020; Tabassum et al., 2020). This is not happened just because of uncontrolled viral replication but also because of an uncontrolled immune reaction from the host. In existence of uncontrolled viral replication, the presence of an increased number of damaged McGoogan, 2020). However, up to $10 \%$ of patients with COVID-19 may develop severe pneumonia with

[Citation: Rana, M.A., Hashmi, M.S., Pervaiz, R., Qayyum, A., Saif, M.M.U., Munir, M.F., Hafeez, M.M. (2021). Beneficial effects of treatment with tocilizumab in critically ill COVID-19 patients. Pak. J. Inten. Care Med. 2021: 9 https://doi.org/10.54112/pjicm.v2021i1.9] 
epithelial cells and cell debris activate a massive cytokine release also known as cytokine storm (Shi et al., 2020). Elevated pro-inflammatory cytokines and inflammatory biomarkers such as interleukin 6, Creactive protein (CRP), and ferritin have been shown to be higher in patients with severe COVID-19 and predictors of mortality (Qin et al., 2020; Ruan et al., 2020). In one study, the level of interleukin 6 was noted to be 10 times higher in critically ill COVID-19 patients who required mechanical ventilation or vasopressor support compared to those with milder disease and interleukin 6 level correlated with the detection of SARS-CoV-2 RNA (Chen et al., 2020). These findings suggest that anti-cytokine targeted therapies might be of benefit for patients with severe COVID-19. TOCILIZUMAB, a monoclonal antibody against interleukin 6 receptor, was previously approved by Food and Drug Administration for the treatment of cytokine release syndrome (Le et al., 2018) and may provide clinical benefit for selected COVID-19 patients with high inflammatory biomarkers.

\section{METHODOLOGY}

The patients infected with COVID-19, who were treated with tocilizumab from May 1st to 5th July 2020 at Bahria international Hospital Lahore, were recruited in this retrospective study. All patient's identity kept anonymous. Total of 431patients medical record were reviewed. 136 patients were given tocilizumab. Out of 136, sixteen patients had missing data were excluded from the study. The study was approved by the ethical committee of Bahria International Hospital Lahore. The data of demographics, laboratory results, and clinical outcomes of the patients were obtained from the medical records. Based on Diagnosis and Treatment of Pneumonia Infected by COVID-19 that was classified into four types: mildly ill, moderately ill, seriously ill and critically ill. The serum levels of CRP, D-Dimers and serum Ferritin level observed before and after tocilizumab administration. CRP, an acute-phase reactant reflecting the inflammatory activity, was defined as elevated when it was higher than $5.0 \mathrm{mg} / \mathrm{L}$. The most recent CRP, D-Dimers and serum Ferritin level was noted before and after the tocilizumab therapy and the changes of the value was observed for 10 days. The clinical outcome of the patients was also evaluated within 10 days after tocilizumab therapy. Statistical analysis was done with SPSS, version 21.0. Data were presented as median (min-max) or as the number and percentage, as appropriate. The Wilcoxon signed-rank test used to compare parameters whenever appropriate. A
$P$-value of less than .05 was considered statistically significant.

\section{RESULTS}

120 patients (94 males and 26 females) infected with COVID-19, confirmed on RT-PCR, were included in this study. The characteristics of patients, the use of TOCILIZUMAB and other anti-inflammatory drugs are summarized in results. The mean age (min-max) of the patients was 53.83 (14-81) years. Out of 120 participants $8(6.6 \%)$ patients were mildly ill, $18(14.8 \%)$ patients were moderately ill, 54 (44.3\%) patients were seriously ill, and $40(32.8 \%)$ patients were critically ill. All (100\%) patients received tocilizumab; the dose of tocilizumab used in patients was the range from 400 to $800 \mathrm{mg}$. Main concern of this study was to see the effect of tocilizumab on improvement of PF Ratio and CRP reduction in Covid-19 infected patients as mentioned in results PF ratio improved in COVID-19 patients after administration of tocilizumab the median of PF Ratio before treatment was 108 (52-362) and improved up to $128(37-406)$ after tocilizumab therapy. The median of PF Ratio before treatment was 108 (52362 ) and improved up to 128 (37-406) after tocilizumab therapy. Laboratory perimeters included in this study were CRP, Serum Ferritin, D-Dimers and $\mathrm{LDH}$. The values of these parameters prior to tocilizumab administration have been significantly increased. Mean CRP (min-max) before administration of tocilizumab was $110(8-239) \mathrm{mg} / \mathrm{L}$. The values of D-Dimers, Serum Ferritin and serum LDH were 567 (141-1620), 105 (831-1678), and 128 (447-1485) respectively. Results showed CRP levels were rapidly decreased up to 40 (9.6-73) $\mathrm{mg} / \mathrm{L}$ after the treatment with the tocilizumab as compared to other laboratory parameters, which were not decreased as significantly. D-Dimers after tocilizumab therapy was 149 (529-1600). On the other hand, the levels of serum Ferritin 183 (823-1637) and LHD increased to 186 (486-2717). Importantly the effect of tocilizumab on CRP was remarkable as it decreases from $110(8-239) \mathrm{mg} / \mathrm{L}$ to 40 (9.6-73) $\mathrm{mg} / \mathrm{L} \quad(\mathrm{P}<.05)$, in this regard other parameters were constant or changed minimally. Although tocilizumab has benefits in relieving inflammatory activity, for critically ill patients who received only a single dose of tocilizumab therapy, there were still deaths reported and the CRP level in the rest 5 patients failed to return to normal range during the 10 days long session. In the other patients, CRP levels were at or near the normal range within 10 days. To measure the median difference of lab values and effectiveness of tocilizumab on those

[Citation: Rana, M.A., Hashmi, M.S., Pervaiz, R., Qayyum, A., Saif, M.M.U., Munir, M.F., Hafeez, M.M. (2021). Beneficial effects of treatment with tocilizumab in critically ill COVID-19 patients. Pak. J. Inten. Care Med. 2021: 9 https://doi.org/10.54112/pjicm.v2021i1.9] 
parameters Wilcoxon's Rank test was used.

Table 1: PF Ratio and Inflammatory Parameters Before and After The Treatment With Tocilizumab

\begin{tabular}{llll} 
Wilcoxon's ranks & & $\mathrm{N}$ & Mean Rank \\
\hline CRP After TOCILIZUMAB Therapy - CRP & Negative Ranks & $120^{\mathrm{a}}$ & 60.50 \\
Before TOCILIZUMAB Therapy & & \\
& Positive Ranks & $0^{\mathrm{b}}$ & .00 \\
& Ties & $0^{\mathrm{c}}$ & \\
& Total & 120 & \multirow{2}{*}{59.16} \\
Post PF Ratio After TOCILIZUMAB - Pre-PF & Negative Ranks & $25^{\mathrm{m}}$ & \\
Ratio Before TOCILIZUMA & Positive Ranks & $95^{\mathrm{n}}$ & 60.85 \\
& Ties & $0^{\mathrm{o}}$ & \\
& Total & 120 & \\
D-Dimers After TOCILIZUMAB Therapy - D- & Negative Ranks & $46^{\mathrm{d}}$ & 60.20 \\
Dimers Before TOCILIZUMAB Therapy & Positive Ranks & $64^{\mathrm{e}}$ & 52.13 \\
& Ties & $10^{\mathrm{f}}$ & \\
& Total & 120 & \\
Ferritin After TOCILIZUMAB Therapy - & Negative Ranks & $53^{\mathrm{g}}$ & 27.52 \\
Ferritin Before TOCILIZUMAB Therapy & Positive Ranks & $57^{\mathrm{h}}$ & 28.43 \\
& Ties & $10^{\mathrm{i}}$ & \\
Total & 120 & \\
LDH After TOCILIZUMAB Therapy - LDH & Negative Ranks & $40^{\mathrm{j}}$ & 29.50 \\
Before TOCILIZUMAB Therapy & Positive Ranks & $72^{\mathrm{k}}$ & 27.94 \\
& Ties & $8^{\mathrm{l}}$ & \\
& Total & 120 & \\
\hline
\end{tabular}

Table 1 elaborate the Wilcoxon's rank test description according to the table 1st pair describes the median CRP before and after tocilizumab therapy in this case three ranks seen. In these results all 120 were negative ranks its mean that the median of CRP in all patients decreased significantly in posttest. 2nd rows describe the effect of tocilizumab therapy in improvement of PF Ratio according to given results there are 95 Positive Ranks and 25 negative Ranks its mean that in maximum cases PF ratio was Low before tocilizumab administration in 95 patients and improved after tocilizumab therapy, only 25 cases not improved after tocilizumab administration. 3rd pair report the D-Dimers median before and after, there were 46 negative ranks, 64 positive ranks and 10 ties mean pre and post equal. According to given values of D-dimers only 46 ranks show the decrease in posttest 64 positive ranks showed the increase in posttest, so d-dimers values not decreased as CRP, after tocilizumab therapy. In the case of ferritin and LDH the results were same as the d-dimers showed in ferritin row only 53 were negative ranks, 57 were positive and 10 were ties which described that ferritin also remained same or higher. According to last row the median LDH was also same as ferritin because there were 40 negative 72 positive and 8 ties which elaborated that maximum patients LDH was high in post-test and some cases have same value of LDH in pre and post test results.

Table 2 Effect of Tocilizumab Treatment on PF Ratio and Inflammatory Parameters

\begin{tabular}{|c|c|c|c|c|c|}
\hline \multicolumn{6}{|c|}{ Test Statistics ${ }^{\text {a }}$} \\
\hline & $\begin{array}{l}\text { CRP after } \\
\text { tocilizumab } \\
\text { therapy - CRP } \\
\text { before } \\
\text { tocilizumab } \\
\text { therapy }\end{array}$ & $\begin{array}{l}\text { D-dimers after } \\
\text { tocilizumab therapy } \\
\text { - D-dimers before } \\
\text { tocilizumab therapy }\end{array}$ & $\begin{array}{l}\text { Ferritin after } \\
\text { tocilizumab } \\
\text { therapy - Ferritin } \\
\text { before } \\
\text { tocilizumab } \\
\text { therapy }\end{array}$ & $\begin{array}{l}\text { LDH after } \\
\text { tocilizumab } \\
\text { therapy - LDH } \\
\text { before } \\
\text { tocilizumab } \\
\text { therapy }\end{array}$ & $\begin{array}{l}\text { Post PF Ratio } \\
\text { after tocilizumab } \\
\text { - Pre-PF ratio } \\
\text { before } \\
\text { tocilizumab }\end{array}$ \\
\hline Z & $-9.508^{b}$ & $-.846^{c}$ & $-.565^{\mathrm{c}}$ & $-2.329^{c}$ & $-5.633^{d}$ \\
\hline $\begin{array}{l}\text { Asymp. Sig. (2- } \\
\text { tailed) }\end{array}$ & .000 & .398 & .572 & .020 & .000 \\
\hline
\end{tabular}

[Citation: Rana, M.A., Hashmi, M.S., Pervaiz, R., Qayyum, A., Saif, M.M.U., Munir, M.F., Hafeez, M.M. (2021). Beneficial effects of treatment with tocilizumab in critically ill COVID-19 patients. Pak. J. Inten. Care Med. 2021: 9 https://doi.org/10.54112/pjicm.v2021i1.9] 
a. Wilcoxon Signed Ranks Test, b. Based on positive ranks, c. Based on negative ranks, d. Based on negative ranks.

Table No: 2 describe the significance of tocilizumab on the $\mathrm{pF}$ ratio and inflammatory markers. Results showed statistically significant improvement in PF ration $(\mathrm{p}<0.001)$ and significant decrease in CRP levels ( $\mathrm{p}<0.001)$ after the administration of tocilizumab. The other parameters D. Dimers, serum ferritin and LDH was not significantly improved $(\mathrm{p}=$ $0.352,0.522$, and 0.201 respectively) in our study.

\section{DISCUSSION}

The result of our study is found to be similar with other studies in improving the PF ratio and decreasing the $\mathrm{C}$ - reactive protein after tocilizumab administration. In our study 120 patients (78\%) 94 males and $(21 \%) 26$ females with COVID-19 were included. The mean age (min-max) of the patients was 53.83 (14-81) years. The dose of tocilizumab used in our study was also similar to the other studies and recommended by the scientific organizations (Melody et al., 2020). A study narrated that at admission, 25 patients had a fever, which resolved in 24 patients within 24 hours of the treatment. Furthermore, $\mathrm{PaO} 2 / \mathrm{FiO} 2$ ( $\mathrm{mm} \mathrm{Hg}$ ) improved during the follow-up period (baseline, $152 \pm 53$; day 7, $283.73 \pm 115.9$; day $14,302.2 \pm 126 ; \mathrm{p}<.05)$. also, the CRP, ferritin, and d-dimer levels and lymphocyte count improved (Khiali et al., 2020). (12). Similar results were seen in our study where after the administration of tocilizumab pf ratio improved significantly. Similarly a study conducted in march 2020 described the effectiveness of tocilizumab in treatment of covid-19 tocilizumab prove as main factor for improving oxygenation and decreasing CRP up to normal levels and a later gradual decrease of il-6 might partly benefit from the inhibition of inflammatory activity by tocilizumab that resulting in stabilization or improvement of clinical outcome (Luo et al., 2020). Another study described the similar results where the CRP levels were far above the normal range in all patients before the start of tocilizumab therapy and were rapidly ameliorated after the tocilizumab treatment. the value of CRP at the first time it was detected after tocilizumab therapy was significantly decreased compared with before tocilizumab therapy, which dropped from $126.9(10.7-257.9)$ to $11.2(0.02-113.7) \mathrm{mg} / \mathrm{l}(\mathrm{p}<.01)$

(Moreno-Pérez et al., 2020)

\section{CONCLUSION}

Tocilizumab effectively improved PF ratio and CRP levels in COVID-19 patients but other markers not seen improved in response to tocilizumab in severely ill COVID-19 patients. Tocilizumab may be considered as an effective treatment in severe patients of COVID-19, which provided a therapeutic strategy for this fatal infectious disease, furthermore our result should be evaluated with caution although we reported a good response in patients with tocilizumab.

\section{LIMITATION}

The number of cases reported is still small and using laboratory parameters to define the disease activity is still challenging.

\section{CONFLICT OF INTEREST}

Authors declare no conflict of interest.

\section{FUNDING}

This study is not funded by any thirst party.

\section{DISCLOSURE}

The preliminary results of this study can be found in BMJ preprint as (Tocilizumab is associated with reduction in inflammation and improvement in $\mathrm{P} / \mathrm{F}$ $\underline{\text { ratio in critically sick COVID19 patients }}$ medRxiv). REFERENCES

Ali, J., Ali, Q., Hafeez, M. M., and Malik, A. (2020). CLINICAL FEATURES, DIAGNOSIS AND TREATMENT OF COVID-19. Biological and Clinical Sciences Research Journal 2020.

Bedford, J., Enria, D., Giesecke, J., Heymann, D. L., Ihekweazu, C., Kobinger, G., Lane, H. C., Memish, Z., Oh, M.-d., and Schuchat, A. (2020). COVID-19: towards controlling of a pandemic. The Lancet 395, 1015-1018.

Chen, X., Zhao, B., Qu, Y., Chen, Y., Xiong, J., Feng, Y., Men, D., Huang, Q., Liu, Y., and Yang, B. (2020). Detectable serum SARSCoV-2 viral load (RNAaemia) is closely correlated with drastically elevated interleukin 6 (IL-6) level in critically ill COVID-19 patients. Clinical Infectious Diseases.

Guan, W.-j., Ni, Z.-y., Hu, Y., Liang, W.-h., Ou, C.q., He, J.-X., Liu, L., Shan, H., Lei, C.-1., and Hui, D. S. (2020). Clinical characteristics of coronavirus disease 2019 in China. New England journal of medicine 382, 17081720.

Huang, C., Wang, Y., Li, X., Ren, L., Zhao, J., Hu, Y., Zhang, L., Fan, G., Xu, J., and Gu, X. (2020). Clinical features of patients infected with 2019 novel coronavirus in Wuhan, China. The lancet 395, 497-506.

Khiali, S., Khani, E., and Entezari-Maleki, T. (2020). A Comprehensive Review of Tocilizumab in COVID-19 Acute Respiratory Distress 
Syndrome. The Journal of Clinical Pharmacology 60, 1131-1146.

Le, R. Q., Li, L., Yuan, W., Shord, S. S., Nie, L., Habtemariam, B. A., Przepiorka, D., Farrell, A. T., and Pazdur, R. (2018). FDA approval summary: tocilizumab for treatment of chimeric antigen receptor $\mathrm{T}$ cell-induced severe or life-threatening cytokine release syndrome. The oncologist 23, 943.

Luo, P., Liu, Y., Qiu, L., Liu, X., Liu, D., and Li, J. (2020). Tocilizumab treatment in COVID-19: A single center experience. Journal of medical virology 92, 814-818.

Mady, A. F., Ramdan, O., Al Yousef, R., Ishag, A., Bakirova, G., Kuhail, A., Shahzad, S., ElEtreby, W., Mumtaz, S., Almozainy, S., Palacio, K., Aldamahshi, D., Alcazar, A., Alodat, M., Abdelrahman, B., and Harthy, A. (2020). COVID 19 CRITICAL CARE TRAINING SURGE EXPERIENCE FOR PHYSICIANS IN RIYADH HEALTH CLUSTER ONE, SAUDI ARABIA. Biological and Clinical Sciences Research Journal 2020.

Melody, M., Nelson, J., Hastings, J., Propst, J., Smerina, M., Mendez, J., and Guru, P. (2020). Case report: use of lenzilumab and tocilizumab for the treatment of coronavirus disease 2019. Immunotherapy.

Moreno-Pérez, O., Andres, M., Leon-Ramirez, J.-M., Sánchez-Payá, J., Rodríguez, J. C., Sánchez, R., García-Sevila, R., Boix, V., Gil, J., and Merino, E. (2020). Experience with tocilizumab in severe COVID-19 pneumonia after 80 days of follow-up: A retrospective cohort study. Journal of autoimmunity, 102523.

Qin, C., Zhou, L., Hu, Z., Zhang, S., Yang, S., Tao, Y., Xie, C., Ma, K., Shang, K., and Wang, W. (2020). Dysregulation of immune response in patients with COVID-19 in Wuhan, China. Clinical Infectious Diseases.

Ruan, Q., Yang, K., Wang, W., Jiang, L., and Song, J. (2020). Clinical predictors of mortality due to COVID-19 based on an analysis of data of 150 patients from Wuhan, China. Intensive care medicine 46, 846-848.

Shi, Y., Wang, Y., Shao, C., Huang, J., Gan, J., Huang, X., Bucci, E., Piacentini, M., Ippolito, G., and Melino, G. (2020). COVID-19 infection: the perspectives on immune responses. Nature Publishing Group.
Siddique, A., Fateh, A., Idrees, N., Ali, Q., Hafeez, M. M., and Malik, A. (2020). THE EPIDEMICS OF COVID-19. Biological and Clinical Sciences Research Journal 2020.

Tabassum, S. A., Bibi, T., Tariq, F., Tariq, S., Raza, S., Hafeez, M. M., and Rana, M. A. (2020). UNUSUAL LEUKEMOID REACTION IN A COVID-19 PATIENT: A CASE REPORT. Biological and Clinical Sciences Research Journal 2020.

Wu, Z., and McGoogan, J. M. (2020). Characteristics of and important lessons from the coronavirus disease 2019 (COVID-19) outbreak in China: summary of a report of 72314 cases from the Chinese Center for Disease Control and Prevention. Jama 323, 1239-1242.

Xu, Z., Shi, L., Wang, Y., Zhang, J., Huang, L., Zhang, C., Liu, S., Zhao, P., Liu, H., and Zhu, L. (2020). Pathological findings of COVID-19 associated with acute respiratory distress syndrome. The Lancet respiratory medicine 8, 420-422.

\section{(2) $(1) \Theta$}

Open Access This article is licensed under a Creative Commons Attribution 4.0 International License, which permits use, sharing, adaptation, distribution and reproduction in any medium or format, as long as you give appropriate credit to the original author(s) and the source, provide a link to the Creative Commons licence, and indicate if changes were made. The images or other third party material in this article are included in the article's Creative Commons licence, unless indicated otherwise in a credit line to the material. If material is not included in the article's Creative Commons licence and your intended use is not permitted by statutory regulation or exceeds the permitted use, you will need to obtain permission directly from the copyright holder. To view a copy of this licence, visit http://creativecommons.org/licen ses/by/4.0/.

(C) The Author(s) 2021

[Citation: Rana, M.A., Hashmi, M.S., Pervaiz, R., Qayyum, A., Saif, M.M.U., Munir, M.F., Hafeez, M.M. (2021). Beneficial effects of treatment with tocilizumab in critically ill COVID-19 patients. Pak. J. Inten. Care Med. 2021: 9 https://doi.org/10.54112/pjicm.v2021i1.9] 